\title{
Promoter methylation and expression analysis of MGMT in advanced pediatric brain tumors
}

\author{
IACOPO SARDI ${ }^{1}$, VALENTINA CETICA ${ }^{1}$, MAURA MASSIMINO ${ }^{3}$, ANNA MARIA BUCCOLIERO ${ }^{4}$, \\ LAURA GIUNTI $^{1}$, LORENZO GENITORI ${ }^{2}$ and MAURIZIO ARICÒ ${ }^{1}$ \\ ${ }^{1}$ Department of Pediatric Hematology-Oncology, ${ }^{2}$ Division of Neurosurgery, A.U.O. \\ ‘Anna Meyer' Florence; ${ }^{3}$ Pediatric Neuro-oncology Unit, Istituto Nazionale Tumori, Milan; \\ ${ }^{4}$ Department of Human Pathology and Oncology, Florence University Medical School, Florence, Italy
}

Received February 26, 2009; Accepted May 8, 2009

DOI: 10.3892/or_00000499

\begin{abstract}
Insufficient response to oral temozolomide (TMZ) in children with brain tumor may depend on the repair-action of inducible $\mathrm{O}^{6}$-methylguanine-DNA methyltransferase (MGMT). To investigate the clinical relevance of MGMT expression, we analyzed MGMT levels by qRT-PCR and immunohistochemistry, and the methylation of gene promoter in patients with relapsed or refractory brain tumor, enrolled in an off-label trial with oral temozolomide. The drug was administered at the dose of $200 \mathrm{mg} / \mathrm{m}^{2} /$ day in patients with no prior cranio-spinal irradiation, and $180 \mathrm{mg} / \mathrm{m}^{2} /$ day in those with previous radiotherapy and/or high-dose chemotherapy followed by autologous hematopoietic stem cell rescue. Nine patients with recurrent ependymoma $(n=3)$, low grade glioma $(n=3)$, glioblastoma $(n=1)$, relapsed medulloblastoma $(n=2)$ were enrolled in the study. Median absolute MGMT mRNA expression level standardized for GAPDH was 1.06 (range -0.453 to 3.932 ). The median relative expression level ( $\mathrm{RQ}=2^{-\mathrm{ddC}}$ ) was 4.29 (range 1.585 to 12.228 ). By immunohistochemistry, the score was $2+$ in 6 of the 9 tumor samples, and $1+$ in 3 , while none was MGMT negative. Methylation of MGMT promoter was detected in only one ependymoma sample. The heterogeneous PFS in our patients treated with second line TMZ, indicates that MGMT expression alone is insufficient to predict the response to TMZ, presumably because of the DNA repair mechanisms involved.
\end{abstract}

Correspondence to: Dr Iacopo Sardi, Department of Pediatric Hematology-Oncology, University of Florence, A.O.U. Meyer Children's Hospital, Viale Pieraccini 24, 50139 Florence, Italy E-mail: i.sardi@meyer.it

Abbreviations: TMZ, temozolomide; MGMT, $\mathrm{O}^{6}$-methylguanineDNA methyltransferase; HGG, high grade glioma; LGG, low grade glioma; GBM, glioblastoma multiforme; PFS, progression-free survival

Key words: temozolomide, alkylanting agents, expression analysis, $\mathrm{O}^{6}$-methylguanine-DNA methyltransferase

\section{Introduction}

Temozolomide (TMZ) is a second-generation alkylating agent that undergoes spontaneous conversion into the active form under physiological conditions, independently of hepatic metabolism. Its ability to diffuse in all tissues including the central nervous system (CNS), together with reduced toxicity compared with its parent compounds, as dacarbazine, made TMZ an interesting agent for treatment of brain tumors (1-3). Its antineoplastic activity in recurrent anaplastic astrocytoma and newly diagnosed glioblastoma (GBM) is known for over 10 years $(4,5)$. In a small cohort of patients with CNS tumor refractory to standard chemotherapy, therapeutic activity of a second line program based on TMZ was reported by De Sio and coworkers (6). Otherwise, in a phase II study of relapsed or progressive high grade and intrinsic brainstem glioma, the cooperative French/UK group reported no convincing evidence of efficacy (7). Thus, therapeutic efficacy of TMZ in refractory brain tumors remains controversial. In particular, whether any efficacy extends to refractory brain tumors in children needs to be clarified. To this point, it may be of interest that TMZ showed significant activity against pediatric solid tumor xenograft models (8).

Therapeutic response to alkylating agents depends also on activity of DNA repair genes, such as $\mathrm{O}^{6}$-methylguanineDNA methyltransferase (MGMT). Evidence of overexpression of MGMT, documented by immunoblot analysis, predicts intrinsic resistance to TMZ; otherwise, in the absence or with very low level of MGMT, proficient mismatch repair systems determine sensitivity to this drug (8). Methylation of MGMT promoter leads to its silencing thus preventing repair of the DNA damage induced by alkylating agents including TMZ, as documented by Paz et al in a series of 92 primary gliomas (9). Based on their observation on a series of 206 GBM patients, Hegi et al concluded that no clinical response may be anticipated in patients without MGMT promoter methylation in the lesional tissue (10).

To address the issue of the role of MGMT methylation in children with brain tumor, we examined the promoter methylation status and expression level of MGMT in tumor samples from nine patients with relapsed disease. This information was compared to the clinical response to $\mathrm{TMZ}$ in a prospective trial. 


\section{Materials and methods}

Study population. All patients with recurrent brain tumor seen between 2003 and 2007 at our institution (AUO Meyer, Florence) were eligible for this study. Histological diagnosis and tumor grading were carried out based on the 2007 World Health Organization (2007-WHO) criteria (11). The study was approved by the institutional Ethics Committee. Informed consent was obtained from the parents or legal guardians in all cases. Nine patients were enrolled in the study. Their histological diagnoses were: ependymoma (EP, WHOgrade III) in three cases, relapsed or progressive low grade gliomas (LGG WHO-grade II) in three cases, glioblastoma (GBM, WHO-grade IV) in one case, medulloblastoma (WHOgrade IV) in two. Their main clinical characteristics are summarized in Table I. Median age at the time of diagnosis was 7.3 years (range 1-16 years). All had been treated with chemotherapy and/or radiotherapy according to current frontline therapeutic studies of the Associazione Italiana Ematologia Oncologia Pediatrica (AIEOP). All underwent surgery for resection of relapsed disease, which turned to be complete in 3 of 9 cases.

Chemotherapy protocol. All patients received TMZ after surgery. Each course of TMZ (Temodal ${ }^{\circledR}$ ) consisted of $200 \mathrm{mg} /$ $\mathrm{m}^{2}$ in a single daily dose for five consecutive days (7). Patients with previous radiotherapy and/or high-dose chemotherapy followed by autologous hematopoietic stem cell rescue received a reduced dose of $180 \mathrm{mg} / \mathrm{m}^{2} /$ day. The intention to treat was to administer nine courses, 28 days apart.

Response criteria. Extent of disease was assessed by contrastenhanced cranial MRI scan at the time of study entry and then every two courses. Two perpendicular dimensions were determined as indicated in RECIST criteria (12). The following categories were used for evaluation of response: (i) complete response (CR) was defined as the disappearance of all known disease for at least 4 weeks; (ii) partial response (PR) as at least $30 \%$ reduction in the longest diameter of measurable lesions for at least 4 weeks; (iii) stable disease (SD) when neither PR nor PD criteria are met; and (iv) progressive disease (PD) as at least $20 \%$ increase in the longest diameter of target lesions or the appearance of new lesions (13).

Statistical analysis. The main clinical endpoint of the study was progression-free survival (PFS), defined as the interval between the first day of the first cycle of TMZ and the occurrence of tumor progression.

Promoter methylation analysis; MGMT molecular analysis. This study was performed on 9 samples of relapsed brain tumor. Methylation-specific PCR (MS-PCR) is a technology for the analysis of DNA methyl-ation in the $\mathrm{CpG}$ islands of the MGMT promoter after sodium bisulfite modification. In the bisulfite reaction, all unmethyl-ated cytosines are converted to uracils, while 5-methyl-cytosines remain unaltered. Methylation-specific PCR (MSP) was performed with primers specific for either methylated or modified unmethylated DNA. Genomic DNA from tumor tissue and peripheral blood were extracted with QIAamp DNA kit
(Qiagen, Milan, Italy) according to the manufacturer's protocol. DNA (500 ng) in a volume of $70 \mu 1$ was denatured with freshly prepared $3 \mathrm{M}$ sodium hydroxide for $10 \mathrm{~min}$ at $37^{\circ} \mathrm{C}, 3 \mathrm{~min}$ at $95^{\circ} \mathrm{C}$ and immediatly placed on ice. A solution of $40 \mathrm{mM}$ hydroquinone (Sigma-Aldrich, Milan, Italy) and 2.8 M sodium bisulfite (Sigma-Aldrich) at pH 5.0 was added and mixed and the samples were incubated at $55^{\circ} \mathrm{C}$ for $16-20 \mathrm{~h}$ in dark. DNA samples were purified from free bisulfite with the Wizard DNA clean-up system (Promega, Madison, WI) and eluted into $100 \mu \mathrm{l}$ of water, again treated with $3 \mathrm{M}$ sodium hydroxide for $15 \mathrm{~min}$ at $37^{\circ} \mathrm{C}$, neutralized with $6 \mathrm{M}$ ammonium acetate and precipitated with 2 volumes of cold absolute ethanol. DNA was resuspended in $20 \mu \mathrm{l}$ of water. Each tumor control DNA for methylated MGMT promoter $\left(\mathrm{CpGenome}^{\mathrm{TM}}\right.$ Universal Methylated DNA, Chemicon International, Temecula, CA) and control DNA for the unmethylated MGMT promoter (DNA from normal peripheral blood), after bisulfite modification, were amplified with met and unmet primers. Primer sequence for the methylated reaction were 5'-TTTCGACGTTCGTAGGTTTTCGC-3' (forward primer) and 5'-GCACTCTTCCGAAAACGAAACG-3' (reverse primer) and for the unmethylated reaction were TTTGTG TTTTGATGTTTGTAGGTTTTTGT-3' (forward primer) and 5'-AACTCCACACTCTTCCAAAAACAAAACA-3' (reverse primer). The methylation-specific PCR was carried out in $25 \mu \mathrm{l}$ reaction mixture containing $5 \mu \mathrm{l}$ of bisulfite-treated genomic DNA, $1 \mathrm{X}$ PCR buffer [Tris.Cl, $\left(\mathrm{NH}_{4}\right)_{2} \mathrm{SO}_{4}, 15 \mathrm{mM}$ $\mathrm{MgCl}_{2} ; \mathrm{pH}$ 8.7] (Qiagen), $200 \mu \mathrm{M}$ dNTPs, $0.5 \mathrm{U}$ HotStarTaq DNA Polimerase (Qiagen) and primers (5 pmol each). The PCR cycle amplification consisted of $95^{\circ} \mathrm{C}$ for 15 min followed by 29 cycles of denaturation at $94^{\circ} \mathrm{C}$ for $1 \mathrm{~min}$, annealing at $59^{\circ} \mathrm{C}$ for $1 \mathrm{~min}$ and extension at $72^{\circ} \mathrm{C}$ for $1 \mathrm{~min}$, and then a final extension at $72^{\circ} \mathrm{C}$ for $10 \mathrm{~min}$ in a PTC 100 Thermal Cycler (MJ Research, Waltham, MA). Twenty microliters of amplified products were loaded onto 4\% Metaphor agarose gel (FMC, Philadelphia, PA) and were visualized by using GelRed $^{\text {TM }}$ (Biotium, Hayward, CA).

$q R T-P C R$ analysis. Lesional RNA was extracted with Qiagen RNeasy MIDI kit and quantified by spectrophotometer. Measurement of gene expression of MGMT (assay on demand, Applied Biosystems) was performed using the ABI Prism $^{\circledR} 7000$ sequence detection system (Applied Biosystems). Prior expression analysis, standard curve was generated for each gene to verify PCR amplification efficiency. Real-time PCR was performed on the corresponding cDNA synthesized from each sample and was repeated in triplicate. The different expression of the target genes normalized to GAPDH were calculated using $\Delta \Delta \mathrm{Ct}$ method, $\Delta \Delta \mathrm{Ct}=\left(\mathrm{CT}_{\text {Target }}-\mathrm{CT}_{\text {Endo }}\right)_{\text {Sample }}-$ $\left(\mathrm{CT}_{\text {Target }}-\mathrm{CT}_{\text {Endo }}\right)_{\text {Reference }}$. The mean and SD were determined from the triplicate samples at each point and data were normalized with Universal Human Reference (Stratagene, La Jolla, CA, USA).

Immunohistochemistry analysis. Sections were mounted on electrostatic slides, deparaffined with xylene and rehydrated by using graded ethanols. Endogenous peroxidase activity was blocked with $3 \%$ hydrogen peroxide in distilled water for $10 \mathrm{~min}$. Antigen was retrieved by microwaving: the sections were immersed in TEC (Tris-EDTA-Citrate) buffer $\mathrm{pH} 7.8$ 
Table I. Clinical characteristics of relapsed or progressive brain tumors.

\begin{tabular}{|c|c|c|c|c|c|c|c|}
\hline ID & $\begin{array}{c}\text { Sex/Age at } \\
\text { diagnosis, years }\end{array}$ & Histology & $\begin{array}{c}\text { Therapy before } \\
\text { TMZ }\end{array}$ & $\begin{array}{c}\text { Last surgery } \\
\text { before } \\
\text { TMZ }\end{array}$ & $\begin{array}{l}\text { Number of } \\
\text { total courses } \\
\text { of TMZ }\end{array}$ & Response & $\begin{array}{c}\text { PFS } \\
\text { (months) }\end{array}$ \\
\hline EP1 & $\mathrm{M} / 8$ & $\begin{array}{c}\text { Anaplastic } \\
\text { ependymoma }\end{array}$ & $\mathrm{SU}+\mathrm{RT}+\mathrm{CT}+\mathrm{SU}$ & GTR & 9 & SD & 12 \\
\hline EP2 & $\mathrm{M} / 11$ & $\begin{array}{c}\text { Anaplastic } \\
\text { ependymoma }\end{array}$ & $\mathrm{SU}+\mathrm{RT}+\mathrm{CT}+\mathrm{SU}$ & PTR & 8 & PD & 10 \\
\hline EP3 & $\mathrm{F} / 16$ & $\begin{array}{c}\text { Anaplastic } \\
\text { ependymoma }\end{array}$ & $\mathrm{SU}+\mathrm{RT}+\mathrm{CT}+\mathrm{SU}$ & GTR & 18 & SD & 24 \\
\hline LGG1 & $\mathrm{M} / 9$ & $\begin{array}{c}\text { Pleomorphic } \\
\text { Xanthoastrocytoma }\end{array}$ & $\mathrm{SU}+\mathrm{CT}+\mathrm{SU}$ & PTR & 9 & SD & 21 \\
\hline LGG2 & $\mathrm{F} / 6$ & $\begin{array}{c}\text { Fibrillary } \\
\text { Astrocytoma }\end{array}$ & $\mathrm{SU}+\mathrm{CT}+\mathrm{CT}+\mathrm{SU}$ & PTR & 9 & SD & 15 \\
\hline LGG3 & $\mathrm{M} / 4$ & $\begin{array}{l}\text { Pylomixoid } \\
\text { Astrocytoma }\end{array}$ & $\mathrm{SU}+\mathrm{CT}+\mathrm{CT}+\mathrm{SU}$ & PTR & 9 & SD & 15 \\
\hline GBM & $\mathrm{M} / 5$ & $\begin{array}{c}\text { Glioblastoma } \\
\text { multiforme }\end{array}$ & $\mathrm{SU}+\mathrm{RT}+\mathrm{CT}+\mathrm{SU}$ & PTR & 2 & PD & 3 \\
\hline MB1 & $\mathrm{F} / 6$ & $\begin{array}{c}\text { Classic } \\
\text { medulloblastoma }\end{array}$ & $\mathrm{SU}+\mathrm{RT}+\mathrm{CT}+\mathrm{SU}$ & GTR & 4 & PD & 5 \\
\hline MB2 & $\mathrm{M} / 1$ & $\begin{array}{c}\text { Classic } \\
\text { medulloblastoma }\end{array}$ & $\mathrm{SU}+\mathrm{CT}+\mathrm{SU}$ & PTR & 6 & PD & 7 \\
\hline
\end{tabular}

EP, ependymoma; MB, medulloblastoma; GBM, glioblastoma multiforme; LGG, low grade glioma; RT, radiotherapy; CT, chemotherapy; SU, surgery; GTR, gross total removal; PTR, partial total removal; PD, progressive disease; SD, stable disease; PFS, progression-free survival

and irradiated for $36 \mathrm{~min}$ in a microwave 'Processing Labstation' (MicroMED T/T Megamilestone Srl Sorisole, Bergamo, Italy). The primary antibody anti-MGMT (Ab1; clone MT3,1; Neo-Markers lab-Vision Corporation) was used at 1:100 dilution at room temperature for $2 \mathrm{~h}$. Then, the sections were incubated with a mouse amplification reagent (Amplification kit; Ventana Medical System) for $10 \mathrm{~min}$ at room temperature. Visualization was obtained by adding a peroxidase conjugated polymer (ChemMate Dako-Envision Detection kit Peroxidase) for 30 min followed by 3,3 diaminobenzidine hydrogen peroxide (ChemMate DAB Chromogen Dako) for $5 \mathrm{~min}$. The nuclei were counterstained with hematoxylin. Positive staining was identified when the nucleus and the cytoplasm were brown. MGMT expression was indicated as negative when it was present in no more than $10 \%$ of the neoplastic cells, as $1+$ when it was present in $>10 \%$ to $50 \%$, and as $2+$ when it was present in $>50 \%$ of the neoplastic cells. The following two conditions were used as negative controls: a non-immune serum in place of the primary antibody; omission of the primary antibody. An ascertained MGMT-positive colon adenocarcinoma tissue was used as positive control.

\section{Results}

Median PFS for the nine patients was 12.4 months (range 3-24 months); at the end of the study all patients were alive, 4 with progressive disease and 5 with stable disease. Three

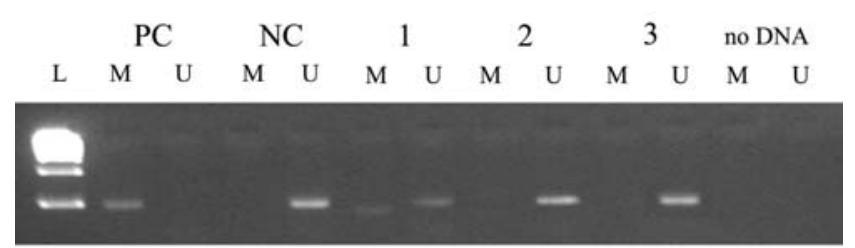

Figure 1. Methylation status of MGMT promoter in brain tumor samples. L, 100 bp marker ladder; PC, positive control for methylated DNA; NC, negative control (DNA from normal blood sample); 1, 4th recurrence of sample EP1; 2, LGG2 sample and 3, GBM sample.

out of 6 patients with measurable disease (LGG1, LGG2 and LGG3) did not progress for 21, 15, and 15 months, respectively. Promoter methylation status, mRNA expression and immunohistochemistry of MGMT for all cases are summarized in Table II. Methylation of MGMT promoter was detected in only one out of 9 specimens (EP1), while the remaining 8 , including all six patients with measurable disease (EP2, LGG1, LGG2, LGG3, GBM and MB2) showed an unmethylated promoter (Fig. 1).

MGMT expression was detected in 9 of 9 samples (Fig. 2). Median absolute MGMT mRNA expression level standardized for GAPDH was 1.06 (range -0.453 to 3.932). Human reference mRNA showed a value of 3.16. The median relative expression level ( $\mathrm{RQ}=2^{-\mathrm{ddC}}$ ) was 4.29 (range 1.585 to 12.228 ).

In immunohistochemistry, 6 tumor samples (67\%), had 


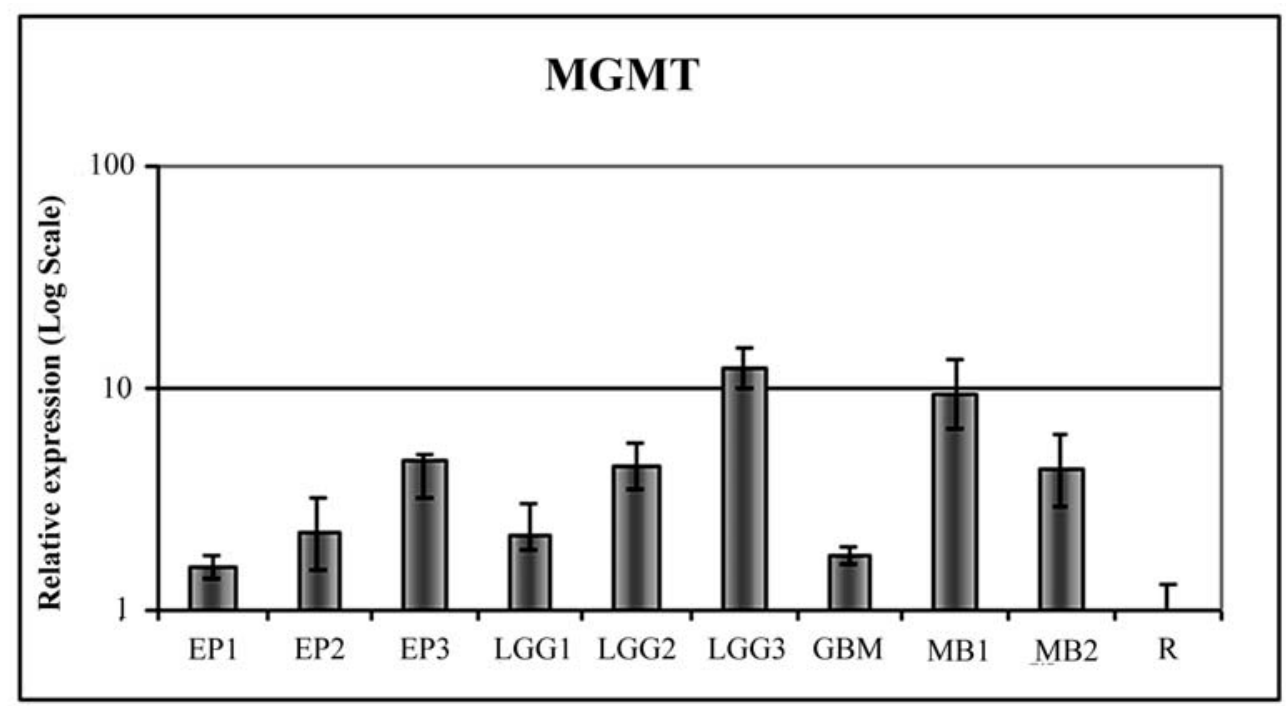

Figure 2. MGMT relative expression (mean values from three replicates) calculated as $2^{\text {-ddCt}}$; R, Human reference.
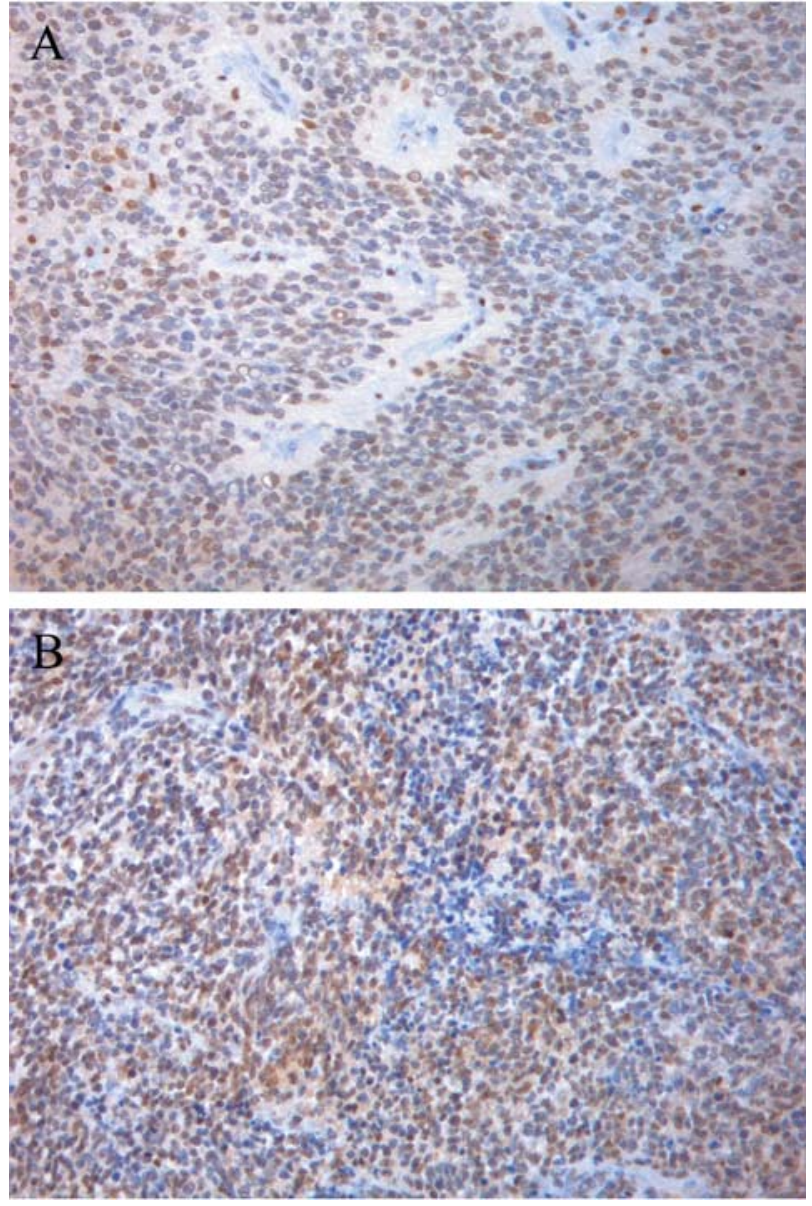

Figure 3. MGMT immunohistochemistry of 2 pediatric brain tumor samples: the tumor cells are moderatly positive in patient EP1 (A) and strongly positive in patient MB1 (B) (original magnification, x100).

score $2+, 3(33 \%)$ had score $1+$, and none was MGMT negative (Fig. 3). All specimens contained perilesional tissue, always MGMT positive: astrocytes, lymphocytes, and endothelial cells were MGMT positive at the cytoplasmic and nuclear level; neurons and oligodendrocytes were MGMT negative. In a single case MGMT promoter was found to be methylated. This was a patient with anaplastic ependymoma (EP1) at the fourth relapse. It was MGMT positive (score 1+) by immunohistochemistry (Table II).

\section{Discussion}

Alkylating agents, such as TMZ, are among the most widely used chemotherapeutic agents in the treatment of brain tumors. Their efficacy, mediated by DNA damage, is greatly dependent on the activity of MGMT, a DNA repair enzyme. The methylation status of its promoter gene has also been related to silencing of MGMT expression and activity.

Our results, although on a small cohort, document that in advanced, either relapsed or progressive, pediatric brain tumor, the expression of MGMT is variable. The methylated MGMT promoter status, with a moderate level of expression of MGMT by both qRT-PCR and immunohistochemistry, was found only in one case (at fourth relapse of EP1). At difference with other studies reporting a correlation between methylation status and response at TMZ, we showed that in pediatric patients the methylated MGMT promoter was, however, characterized by moderate-high expression of MGMT without correlation to clinical response at this agent. Quantitative analysis identifies expression of MGMT mRNA. In our analysis gene expression was considerably high in two samples: case LGG3 and case MB1 that showed a ten-fold logarithmic increment. Lower expression was found in two cases: in case EP1, the finding is in keeping with observed promoter methylation and low protein expression; on the contrary, in case GBM, which shows promoter unmethylation, we suspect that this result may depend on tissue sampling, due to the highly heterogeneous nature of this tumor. Three of the 6 patients with measurable disease did not progress for a median of 17.0 months. In these cases the unmethylated form of the promoter, and a moderate expression of MGMT gene were found by both qRT-PCR and immunohistochemistry analysis. 
Table II. MGMT analysis in relapsed or progressive pediatric brain tumors.

\begin{tabular}{|c|c|c|c|c|}
\hline $\begin{array}{l}\text { Tumor } \\
\text { sample }\end{array}$ & $\begin{array}{c}\text { Promoter status } \\
\text { score }\end{array}$ & $\begin{array}{l}\text { mRNA expression } \\
\text { levels }(\mathrm{dCt})\end{array}$ & $\begin{array}{c}\text { Relative expression } \\
\text { level }\end{array}$ & Immunohistochemistry \\
\hline EP1 & Methylated & 3.82 & 1.585 & 1 \\
\hline EP2 & Unmethylated & 1.99 & 2.246 & 2 \\
\hline EP3 & Unmethylated & 0.96 & 4.605 & 2 \\
\hline LGG1 & Unmethylated & 2.02 & 2.196 & 1 \\
\hline LGG2 & Unmethylated & 1.01 & 4.431 & 2 \\
\hline LGG3 & Unmethylated & -0.45 & 12.228 & 2 \\
\hline GBM & Unmethylated & 3.55 & 1.761 & 1 \\
\hline MB1 & Unmethylated & -0.08 & 9.458 & 2 \\
\hline MB2 & Unmethylated & 1.06 & 4.290 & 2 \\
\hline Human Ref. & - & 3.16 & 1 & - \\
\hline
\end{tabular}

MGMT mRNA expression in tumor samples standardized for GAPDH (mean values from three replicates). EP, ependymoma; LGG, low grade glioma; GBM, glioblastoma multiforme; MB, medulloblastoma. Human Ref, Universal Human Reference RNA (Stratagene). Immunohistochemestry score $0: \leq 10 \% ; 1:>10 \% \leq 50 \% ; 2:>50 \%$.

TMZ showed significant activity against a panel of pediatric solid tumor xenografted in immune-deprived mice. High levels of MGMT by immunoblot analysis predict intrinsic resistance to TMZ, whereas the most responsive tumors are totally deficient or have very low MGMT (8).

Several studies have demonstrated a prognostic impact of MGMT promoter methylation in malignant glioma of adult patients $(9,14)$. A recent pathological study reported that variation in MGMT promoter methylation can occur within different specimens taken from the same tumor before and after adjuvant treatment (15). Hegi et al demonstrated that the patients with newly diagnosed GBM treated with TMZ and radiotherapy containing a methylated MGMT promoter had a survival benefit (10). A retrospective study including 219 adult GBMs showed that methylation status had no impact on PFS and OS though there was a significant advantage for GBM patients treated with RT and adjuvant nitrosourea; particularly, survival curves of patients who received BCNU during the course of $\mathrm{RT}$ showing a clear, positive impact of methylation on survival $(\mathrm{P}=0.0004)(16)$. Donson et al examined the MGMT methylation status in a small cohort of ten pediatric GBM treated with TMZ as part of therapy under a variety of therapeutic protocols, either an initial therapy or relapse. They found that methylation correlated $(\mathrm{P}=0.0005)$ with a longer survival and the mean survival time for patients with methylated MGMT was 13.7 \pm 3.7 months, as compared to $2.5 \pm 1.7$ months for patients with an unmethylated MGMT promoter (17).

A series of studies evaluating the expression of MGMT did not reveal a strictly correlation with methylation status of the promoter gene $(18,19)$. Several MGMT expression analysis have been carried out by immunohistochemistry, even if no method has yet been well standardized. Nakasu et al analyzing neoplastic and non-neoplastic cells of gliomas, found that tumors always presented an MGMT-positive normal cell component. Considering a cut-off point at $10 \%$ of the normal cell component in glioma samples for discriminating the negative tumor from the positive one, they showed that MGMT negative expression tumor was a significant factor for survival $(\mathrm{P}<0.05)$ in the patient treated with ACNU (20).

The expression analysis of MGMT by immunohistochemistry in 109 malignant gliomas from CCG-945 study showed that overexpression was associated with an unfavorable prognosis after alkylating agent chemotherapy administered as a component of a multimodality regimen. The correlation between MGMT overexpression and poor prognosis remained significant independently of a variety of clinical variables such as histology (anaplastic astrocytoma vs. GBM), age, amount of residual tumor and tumor localization (21).

In a series of 93 adult patients with WHO-grade III glioma uniformly treated with adjuvant radiotherapy and chemotherapy (BCNU alone for anaplastic astrocytoma and PCV regimen for those with oligodendritic component) after surgery, it was shown that absence of tumor MGMT expression was independently associated with a longer OS in patients with anaplastic glioma who received chemotherapy, whereas alteration of methylation status had not prognostic implication (18). In adult low grade oligodendroglioma, it was also demonstrated a significant correlation between LOH at chromosome 1p, radiographic response to treatment with TMZ, and low MGMT protein expression evaluated by immunohistochemistry (22).

Presently, qRT-PCR seems to be the most sensitive and rapid system for the quantitation of RNA. The results of new personalized adjuvant therapy based on the data of qRT-PCR for MGMT to treat high grade gliomas seemed to be more effective than conventional therapies. Tumors with a relative quantitation value, expressed as $2^{\text {-ddC }}$, of MGMT $\geq 1$ should not be treated by ACNU. These results showed a close relationship between MGMT expression and the prognosis of HGG patients treated with ACNU (23). The role of methylation status of this gene has been also studied in medulloblastoma/PNET. A study on 37 pediatric medulloblastoma found a methylated MGMT promoter in $28(76 \%)$ 
tumors. Interestingly, they observed that MGMT expression by qRT-PCR varied more than 20 -fold without any correlation with promoter methylation status. Similarly to our data, they demonstrated that all tumors presented an MGMT positive staining in immunohistochemistry analysis (24).

The results showing a low toxicity profile of TMZ have encouraged the use of this second-generation of alkylating agents in refractory tumors such as relapsed or progressive HGGs as well as other high risk pediatric brain tumors. The difference in response to chemotherapy of pediatric brain tumors are striking and, at the present time, not easily explained. Moreover, the repair of cytotoxic DNA damage by MGMT also seems to represent an important factor of chemoresistance to TMZ or other nitrosourea-based drugs as CCNU, commonly used in the treatment of brain tumors. A phase II study from Children's Oncology Group of TMZ in 104 pediatric brain tumors concluded that TMZ activity may be less robust in children even if adult studies confirmed a high response to $\mathrm{TMZ}$ for both low grade and high grade gliomas. A partial response has been obtained both in one high grade and in one low grade gliomas, responses (1 complete and 3 partial) were obtained in 4 out of 25 recurrent medulloblastoma/PNETs, whereas no response among the other patients with ependy-moma, brain stem or other recurrent CNS tumors was reported (25). At present, there is an ongoing phase I/II study of TMZ plus autologous stem cell rescue in therapy of children with newly diagnosed HGG or recurrent brain tumors by Dr Henry Friedman of the Duke Comprehensive Cancer Center in Durham, NC, USA. The use of TMZ alone or combined has produced promising results in phase I/II clinical trials in adult high grade gliomas (HGG) (26-30). A recent study on a small cohort of recurrent or progressive gliomas in adults pre-treated with TMZ showed a reduction of side effects and an objective response respect to other more aggressive treatments (31). TMZ varies in efficacy in the treatment of pediatric brain tumors. De Sio et al reported that TMZ was a well tolerated treatment which showed efficacy in refractory CNS tumors (6). A phase II clinical trial of TMZ administered three times a day for five days at the dosage of $200 \mathrm{mg} / \mathrm{m}^{2} /$ die in pediatric HGG did not show significant responses but only a disease stabilization in around $30 \%$ of relapsed supratentorial gliomas (32). However, the results of a larger phase II study which considered 104 pediatric relapsed brain tumor patients, were not very encouraging, showing a limited overall objective response (25).

The heterogeneous PFS of our patients treated with second line TMZ, indicates that MGMT expression alone is insufficient to predict the response to TMZ at the molecular level, presumably because of the numerous DNA repair mechanisms involved. On the basis of our experience and literature data it is very likely that pediatric brain tumors have nearly always the MGMT promoter at unmethylated status consequently with a high level of this DNA repair enzyme.

In conclusion, the DNA damage of TMZ seems to be repaired by MGMT. This mechanism is likely efficient on the combination of TMZ with other antineoplastic drugs as well, since the main DNA damage of TMZ is the methylation of the $\mathrm{O}^{6}$ position of the guanine which is efficiently removed by MGMT. Waiting for the results of clinical trials which use
TMZ in combination with other antitumoral agents, the treatment with $\mathrm{TMZ}$ alone has low efficacy and does not improve the clinical outcome of refractory pediatric CNS tumors. Further studies are needed to better characterize the role of MGMT gene in the resistance to alkylating agents such as TMZ.

\section{Acknowledgements}

This study was supported by a grant from Associazione Italiana per la Ricerca sul Cancro (AIRC) and by 'NOI PER VOI' Onlus Foundation.

\section{References}

1. Clark AS, Deans B, Stevens MF, Tisdale MJ, Wheelh6ouse RT, Denny BJ and Hartley JA: Antitumor imidazotetrazines. Synthesis of novel imidazotetrazinones and related bicyclic heterocycles to probe the mode of action of the antitumor drug temozolomide. J Med Chem 38: 1493-1504, 1995.

2. Danson SJ and Middleton MR: Temozolomide: a novel oral alkylating agent. Expert Rev Anticancer Ther 1: 13-19, 2001.

3. Nagasubramanian R and Dolan ME: Temozolomide: realizing the promise and potential. Curr Opin Oncol 15: 412-418, 2003.

4. Bower M, Newlands ES, Bleehen NM, et al: Multicentre CRC phase II trial of temozolomide in recurrent or progressive highgrade glioma. Cancer Chemother Pharmacol 40: 484-488, 1997.

5. Stupp R, Mason WP, van den Bent MJ, et al: European Organisation for Research and Treatment of Cancer Brain Tumor and Radiotherapy Groups; National Cancer Institute of Canada Clinical Trials Group. Radiotherapy plus concomitant and adjuvant temozolomide for glioblastoma. N Engl J Med 352: 987-996, 2005.

6. De Sio L, Milano GM, Castellano A, Jenkner A, Fidani P, Dominici C and Donfrancesco A: Temozolomide in resistant or relapsed pediatric solid tumors. Pediatr Blood Cancer 47: 30-36, 2006.

7. Lashford LS, Thiesse P, Jouvet A, et al: A United Kingdom Children's Cancer Study Group and French Society for Pediatric Oncology Intergroup Study. Temozolomide in malignant gliomas of childhood: a United Kingdom Children's Cancer Study Group and French Society for Pediatric Oncology Intergroup Study. J Clin Oncol 20: 4684-4691, 2002.

8. Middlemas DS, Stewart CF, Kirstein MN, Poquette C, Friedman HS, Houghton PJ and Brent TP: Biochemical correlates of temozolomide sensitivity in pediatric solid tumor xenograft models. Clin Cancer Res 6: 998-1007, 2000.

9. Paz MF, Yaya-Tur R, Rojas-Marcos I, et al: CpG island hypermethylation of the DNA repair enzyme methyltransferase predicts response to temozolomide in primary gliomas. Clin Cancer Res 10: 4933-4938, 2004.

10. Hegi ME, Diserens AC, Gorlia T, et al: MGMT gene silencing and benefit from temozolomide in glioblastoma. N Engl J Med 352: 997-1003, 2005.

11. Louis DN, Ohgaki H, Wiestler OD and Cavenee WK (eds): WHO Classification of tumours of the central nervous system. IARC, Lyon, 2007.

12. Padhani AR and Ollivier L: The RECIST (Response Evaluation Criteria in Solid Tumors) criteria: implications for diagnostic radiologists. Br J Radiol 74: 983-986, 2001.

13. Therasse P, Arbuck SG, Eisenhauer EA, et al: New guidelines to evaluate the response to treatment in solid tumors. J Natl Cancer Inst 92: 205-216, 2000.

14. Esteller M, Garcia-Foncillas J, Andion E, et al: Inactivation of the DNA-repair gene MGMT and the clinical response of gliomas to alkylating agents. N Engl J Med 343: 1350-1354, 2000 .

15. Parkinson JF, Wheeler HR, Clarkson A, et al: Variation of O(6)methylguanine-DNA methyltransferase (MGMT) promoter methylation in serial samples in glioblastoma. J Neurooncol 87: 71-78, 2008.

16. Crinière E, Kaloshi G, Laigle-Donadey F, et al: MGMT prognostic impact on glioblastoma is dependent on therapeutic modalities. J Neurooncol 83: 173-179, 2007. 
17. Donson AM, Addo-Yobo SO, Handler MH, Gore L and Foreman NK: MGMT promoter methylation correlates with survival benefit and sensitivity to temozolomide in pediatric glioblastoma. Pediatr Blood Cancer 48: 403-407, 2007.

18. Brell M, Tortosa A, Verger E, et al: Prognostic significance of O6-methylguanine-DNA methyltransferase determined by promoter hypermethylation and immunohistochemical expression in anaplastic gliomas. Clin Cancer Res 11: 5167-5174, 2005.

19. Sasai K, Nodagashira M, Nishihara H, et al: Careful exclusion of non-neoplastic brain components is required for an appropriate evaluation of O6-methylguanine-DNA methyltransferase status in glioma: relationship between immunohistochemistry and methylation analysis. Am J Surg Pathol 32: 1220-1227, 2008.

20. Nakasu S, Fukami T, Baba K and Matsuda M: Immunohistochemical study for O6-methylguanine-DNA methyltransferase in the non-neoplastic and neoplastic components of gliomas. J Neurooncol 70: 333-340, 2004.

21. Pollack IF, Hamilton RL, Sobol RW, et al: O6-methylguanineDNA methyltransferase expression strongly correlates with outcome in childhood malignant gliomas: results from the CCG945 Cohort. J Clin Oncol 24: 3431-3437, 2006.

22. Levin N, Lavon I, Zelikovitsh B, Fuchs D, Bokstein F, Fellig Y and Siegal T: Progressive low-grade oligodendrogliomas: response to temozolomide and correlation between genetic profile and O6-methylguanine DNA methyltransferase protein expression. Cancer 106: 1759-1765, 2006.

23. Tanaka S, Kobayashi I, Utsuki S, et al: O6-methylguanine-DNA methyltranspherase gene expression in gliomas by means of real-time quantitative RT-PCR and clinical response to nitrosoureas. Int J Cancer 103: 67-72, 2003.
24. Rood BR, Zhang $\mathrm{H}$ and Cogen PH: Intercellular heterogeneity of expression of the MGMT DNA repair gene in pediatric medulloblastoma. Neuro Oncol 6: 200-207, 2004.

25. Nicholson HS, Kretschmar CS, Krailo M, et al: Phase 2 study of temozolomide in children and adolescents with recurrent central nervous system tumors: a report from the Children's Oncology Group. Cancer 110: 1542-1550, 2007.

26. Quinn JA, Desjardins A, Weingart J, et al: Phase I trial of temozolomide plus O6-benzylguanine for patients with recurrent or progressive malignant glioma. J Clin Oncol 23: 7178-7187, 2005.

27. Reardon DA, Quinn JA, Rich JN, et al: Phase I trial of irinotecan plus temozolomide in adults with recurrent malignant glioma. Cancer 104: 1478-1486, 2005.

28. Wemmert S, Ketter R, Rahnenfuhrer J, et al: Patients with highgrade gliomas harboring deletions of chromosomes $9 p$ and $10 q$ benefit from temozolomide treatment. Neoplasia 7: 883-893, 2005.

29. Reardon DA, Rich JN, Friedman HS and Bigner DD: Recent advances in the treatment of malignant astrocytoma. J Clin Oncol 24: 1253-1265, 2006

30. Prados MD, Lamborn KR, Chang S, et al: Phase 1 study of erlotinib $\mathrm{HCl}$ alone and combined with temozolomide in patients with stable or recurrent malignant glioma. Neuro Oncol 8: 67-78, 2006

31. Franceschi E, Omuro AM, Lassman AB, Demopoulos A, Nolan C and Abrey LE: Salvage temozolomide for prior temozolomide responders. Cancer 104: 2473-2476, 2005.

32. Ruggiero A, Cefalo G, Garre ML, et al: Phase II trial of temozolomide in children with recurrent high-grade glioma. J Neurooncol 77: 89-94, 2006. 